\title{
Acquisition and extinction effects of partial reinforcement under conditions of thirst motivation
}

\author{
JEFFREY A. SEYBERT and IVAN C. GERARD \\ University of Missouri, Kansas City, Missouri 64110
}

\begin{abstract}
Two experiments investigated the generality of partial reinforcement effects across motivational conditions by examining the effects of partial water reinforcement in thirst motivated rats. In Experiment I, patterned responding was observed for subjects that received a single alternation schedule of reinforced $(\mathrm{R})$ and nonreinforced $(\mathrm{N})$ trials, i.e., they learned to run slower on $\mathrm{N}$ trials than on $R$ trials. Subjects that received a nonalternating partial reinforcement schedule (PRF) did not exhibit patterned responding. In Experiment II, subjects that received PRF were more resistant to extinction than subjects that received continuous reinforcement during acquisition. The data from both experiments suggests a high degree of similarity in the effects of partial reinforcement regardless of appetitive motivational condition.
\end{abstract}

The effects of partial reinforcement (PRF) have been well documented (e.g., Robbins, 1971). Most of the evidence concerning manipulations of PRF, however, is based on data from procedures involving hunger motivation and food reward. Recently, some controversy has arisen in regard to the effects of PRF in situations involving water reinforcement for thirstmotivated animals. While some authors (e.g., Seybert, Gerard, Lawrence, Nash, \& Williams, in press, a; Shanab, Melrose, \& Young, 1975) have observed traditional partial reinforcement extinction effects (PREE-animals receiving partial food reinforcement show greater resistance to extinction than animals receiving continuous food reinforcement) using thirst motivation/water reinforcement procedures, others, notably Macdonald and De Toledo (1974), have failed to do so. Macdonald and De Toledo postulated, on the basis of their results, the existence of differential mechanisms underlying the effects of partial reinforcement as a function of type of appetitive motivation and relevant reward. In an attempt to evaluate the conclusions drawn by Macdonald and De Toledo, the present experiments were designed to investigate two well known, reliable PRF phenomena under conditions of thirst motivation, with water used as reinforcement; namely, the acquisition effects of a single alternation pattern of reinforcement and the extinction effects of partial vs. continuous reinforcement.

\section{EXPERIMENT I}

Experiment I examined a frequently observed PRF acquisition phenomenon known as patterned running,

Requests for reprints should be sent to J. A. Seybert, Department of Psychology, C. B. Annex, University of Missouri, Kansas City, Missouri 64110. or patterning. Patterning refers to the situation wherein rats, if provided with a singly alternating pattern of reinforced (R) and nonreinforced $(\mathrm{N})$ trials (i.e., NRNRNR ...), learn to anticipate the occurrence of $\mathrm{N}$ and $\mathrm{R}$ goal events and respond accordingly, i.e., run slower on $\mathrm{N}$ trials than on $\mathrm{R}$ trials. This finding has been demonstrated in both appetitive instrumental conditioning with food as reward (cf. Capaldi, 1967) and in instrumental escape conditioning (e.g., Seybert, Mellgren, Jobe, \& Eckert, 1974). The present experiment was conducted to determine if thirsty animals which receive a single alternation schedule of water reinforcement would also learn to pattern respond.

\section{Method}

Subjects. The subjects were 20 naive male Sprague-Dawley albino rats (Holtzman Company), approximately 110 days old at the start of training.

Apparatus. The apparatus consisted of a $180 \mathrm{~cm}$ long by $16 \mathrm{~cm}$ high by $13 \mathrm{~cm}$ wide straight-alley runway constructed of $1 / 2$-in. pine, painted with alternate vertical black/white stripes $2.22 \mathrm{~cm}$ wide. In the distal end of the goalbox, an angled hole was drilled to allow insertion of an aluminum drinking tube, which was connected to a plastic water bottle. The subjects' progress in the alley was measured by three .01-sec timers. The first timer, which measured start time, was started by a microswitch at the startbox door and stopped by a photocell located $15 \mathrm{~cm}$ into the alley. The second timer, which measured run time, was started by the first photocell and stopped by a second photocell located $15 \mathrm{~cm}$ in front of the goalbox. The third timer, which measured goal time, was started by the second photocell and stopped by a third photocell located $8 \mathrm{~cm}$ inside the goalbox. Start, run, and goal speeds were obtained by converting the start, run, and goal times to reciprocals. The sums of start, run, and goal times were also converted to reciprocals, yielding a total speed measure.

Procedure. Upon arrival in the laboratory, the subjects were individually housed and placed on a $23 \frac{1}{2}-\mathrm{h}$ water deprivation schedule, food being available ad lib. During the 10 days before the start of the experiment, each subject was handled 5 to 10 
min daily. Two days of pretraining preceded the start of the experiment. On the first day of pretraining each subject received one reinforced trial in the apparatus, and on the second day each subject received two reinforced trials in the apparatus. Throughout the experiment, reinforcement consisted of $20 \mathrm{sec}$ access to the drinking tube in the goalbox, while nonreinforcement consisted of a 20 -sec confinement in the goalbox, with no water available.

Subjects were randomly assigned to one of two groups ( $N=10$ /group), designated SA (single alternation) and $\mathrm{MN}$ (multiple $\mathrm{N}$ lengths; an $\mathrm{N}$ length is the number of consecutive $\mathrm{N}$ trials followed by at least one $\mathrm{R}$ trial). A total of 192 acquisition trials were given, 8 trials per day for 24 days, the ITI being 15-20 sec on all trials.

Both groups received a $50 \%$ PRF schedule during acquisition: Group SA received a single alternation schedule of $N$ and $R$ trials (i.e., NRNRNRNR) on each day of acquisition training, while Group $\mathrm{MN}$ received the following schedules of $\mathrm{N}$ and $\mathrm{R}$ trials: Days 1, 7, 13, 19-RRNNRNNR; Days 2, 8, 14, 20-RNRRNNNR; Days 3, 9, 15, 21-RNRNRNNR; Days 4, 10, 16, 22-NRNNNRRR; Days 5, 11, 17, 23-NRRRNNNR; and Days $6,12,18,24-N N N R N R R R$. The subjects were run in squads of six, three from each group in a squad, throughout training.

\section{Results and Discussion}

The data from all alley segments in both Experiments I and II produced highly similar patterns of results; thus, only the total speed data will be presented and discussed.

The data from Experiment I can be seen in Figure 1. As is clear from the figure, there were no appreciable differences between the groups early in training. In the latter portion of training, however, marked differences can be seen. Specifically, Group SA eventually responded much slower on $\mathrm{N}$ trials than on $\mathrm{R}$ trials, while no such differential responding occurred for Group MN. In order to evaluate these differences, the data from the last 14 days (Days 11-24) of acquisition training were combined into daily blocks of $\mathrm{N}$ and $\mathrm{R}$ trials and subjected to a 2(Groups) by 2(Type of Trial) by 14(Days)

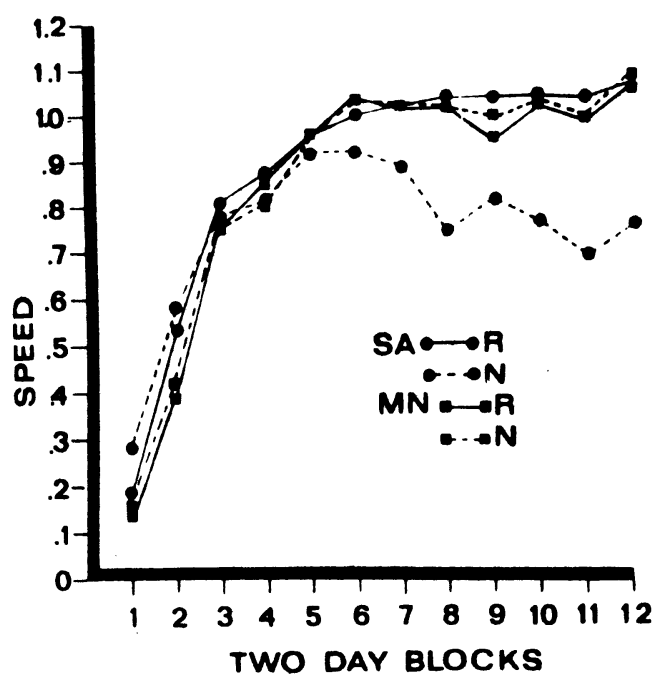

Figure 1. Mean total speeds (in 2-day blocks) on reinforced (R) and nonreinforced (N) acquisition trials for 24 days .of acquisition training. analysis of variance. The major result of the experiment, i.e., the occurrence of patterning in Group SA and its absence in Group $\mathrm{MN}$, was confirmed by the significant Groups by Type of Trial interaction, $F(1,18)=36.27$, $\mathrm{p}<.001$, indicating differential responding as a function of type of trial in one group (SA) and not in the other (MN). This latter contention also receives support from planned comparisons ( $t$ tests) which show that subjects in Group SA ran significantly faster on $R$ than on $N$ trials over the last 14 days of training, $t(18)=4.30$, $\mathrm{p}<.01$, while no speed differences were detected in Group $M N, t<1$. The significant Groups by Type of Trial by Days interaction, $F(13,234)=2.62, p<.01$, indicates that these differences increased over the last 14 days of training (see Figure 1). The main effects of Type of Trial, $F(1,18)=28.53, p<.001$, and Days, $F(13,234)=2.03, p<.05$ were also significant, as were the interactions of Groups by Days, $F(13,234)=2.03$, $p<.05$, and Type of Trial by Days, $F(13,234)=3.75$, $\mathrm{p}<.001$. The Groups main effect failed to reach an acceptable level of significance, $F(1,18)=3.13, p>.05$.

The single alternation patterning which was observed in the present thirst motivation/water reinforcement paradigm is similar to data from analogous procedures using food reward (cf. Capaldi, 1967). The present findings thus suggest a strong correspondence between the effects of PRF regardless of appetitive motivational condition, at least for acquisition. Further, given this correspondence between the acquisition effects of PRF in the two motivational paradigms, it is possible that a similar correspondence exists for the extinction effects of PRF, contrary to the findings of Macdonald and De Toledo. Experiment II tests this possibility.

\section{EXPERIMENT II}

The effects of PRF on the resistance of instrumental behaviors to extinction are well known, i.e., PRF during acquisition generates greater resistance to extinction than does CRF. As mentioned earlier, however, most of the evidence for such effects has come from food reward procedures, although there is considerable recent evidence that similar processes function in instrumental escape conditioning as well (e.g., Seybert et al., 1974; Seybert, Rigby, \& Mellgren, in press, b). As noted previously, there is some disagreement concerning the extinction effects of PRF water reinforcement. Shanab et al. (1975) and Seybert et al. (in press, a) have reported traditional PREEs using thirst motivation/water reinforcement procedures. Macdonald and De Toledo (1974), however, reported no differences in extinction performance between animals that received PRF water reinforcement and animals that received CRF water reinforcement. It has been suggested that several procedural factors may have masked the occurrence of a PREE in the Macdonald and De Toledo study (Seybert et al., in press, a; Shanab et al., 1975). It is the purpose of the present experiment to reexamine the differences 
in extinction, if any, between water-deprived animals which receive $\mathrm{CRF}$ water reinforcement and similar animals which receive PRF water reinforcement.

\section{Method}

Subjects. The subjects were 20 rats similar to those used in Experiment I, except that they were 90 days old at the start of the experiment.

Apparatus. The apparatus was the same as that used in Experiment I.

Procedure. The procedures for housing, deprivation schedule, handling, and pretraining in the present experiment were identical to those used in Experiment I. For the present experiment, reinforcement consisted of $15 \mathrm{sec}$ access to the drinking tube in the goalbox, while nonreinforcement consisted of $15 \mathrm{sec}$ confinement in the goalbox with no water available. The subjects were randomly assigned to one of two groups ( $N=10 /$ group). One group (Group CRF) was reinforced on all acquisition trials. The second group (Group PRF) received 67\% partial reinforcement on the following schedule: Day1-RRRRNR; Day 2-RRNNNR; Day 3-RNNRRR. Acquisition training for all subjects consisted of 6 trials per day for 3 days, for a total of 18 acquisition trials.

Following acquisition, all subjects received 3 extinction trials per day for 5 days, a total of 15 extinction trials. The procedure for extinction trials was exactly the same as that on nonreinforced trials during acquisition. During both acquisition and extinction, the subjects were run in squads of six, two from each group in a squad. The ITI was 5-6 min throughout the experiment.

\section{Results and Discussion}

As can be seen in Figure 2, the differences at the end of acquisition between Group CRF and Group PRF (point A) are very small. This impression was confirmed by a $t$ test conducted on the block of trials from Day 3 of acquisition, $t<1$.

The data from extinction phase (also seen in Figure 2) clearly indicate the superiority of Group PRF over Group CRF. The data were arranged in blocks of three daily trials and analyzed via a 2(Groups) by 5(Days) analysis of variance. As expected, the analysis yielded significant main effects for Days, $F(4,72)=20.57$, $\mathrm{p}<.001$, and Groups, $\mathrm{F}(1,18)=4.52, \mathrm{p}<.05$, indicating that Group PRF was more resistant to extinction than Group CRF. The Groups by Days interaction was

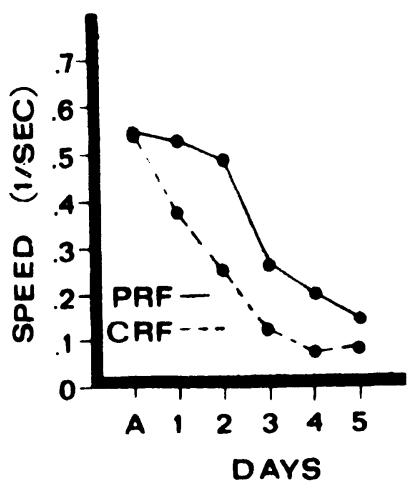

Figure 2. Mean total speeds for the last day of acquisition and 5 days of extinction. not significant, $\mathrm{F}<1$. The present results, demonstrating a PREE in the third motivation/water reinforcement paradigm, are thus in sharp disagreement with those of Macdonald and De Toledo (1974) and confirm the findings of Seybert et al. (in press, a) and Shanab et al.(1975).

\section{GENERAL DISCUSSION}

Together, the results of Experiments I and II demonstrate, under conditions of thirst motivation with water as reinforcement, PRF acquisition and extinction effects (patterning and a PREE, respectively) highly similar to effects obtained from analogous procedures under conditions of hunger motivation with food as reinforcement. The present findings are thus in direct disagreement with the contention of Macdonald and De Toledo that different mechanisms operate, or at least different empirical findings obtain, in PRF procedures using different reinforcers.

The reasons for the discrepancies between Macdonald and DeToledo's results and those of Seybert et al. (in press, a), Shanab et al. (1975), and the present experiments are probably procedural. Macdonald and De Toledo used an extremely small reward magnitude, extremely long ITIs, a latency measure of responding rather than a speed measure, and failed to obtain response measures for the latter portions of the response chain. All of these factors tend to diminish the magnitude of the PREE; thus, it is not surprising that Macdonald and De Toledo failed to observe such an effect. A more complete discussion of these procedural considerations can be found in Seybert et al. (in press, a) and Shanab et al. (1975). Thus, it must be concluded that Macdonald and De Toledo generalized improperly from a procedure involving a number of important limitations. It also seems reasonable to conclude, both from the present findings and the earlier work of Seybert et al. (in press, a) and Shanab et al. that the effects of PRF in both acquisition and extinction are highly similar, regardless of condition of appetitive motivation and relevant reward.

\section{REFERENCES}

CAPALDI, E. J. A sequential hypothesis of instrumental learning. In K. W. Spence \& J. T. Spence (Eds.), The psychology of learning and motivation (Vol. 1), New York: Academic Press, 1967.

Macdonald, G. E., \& De Toledo, L. Partial reinforcement effects and type of reward. Learning and Motivation, 1974, 5, 288-298.

Robsins, D. Partial reinforcement: A selective review of the alleyway literature since 1960. Psychological Bulletin, 1971, 76, 415-431.

Seybert, J. A., Gerard, I. C., Lawrence, W. T., Nash, S. W., \& Williams, C. L. Effects of schedule and magnitude of reinforcement under conditions of thirst motivation. Learning and Motivation, 1976, in press. (a)

Seybert, J. A., Mellgren, R. L., Jobe, J. B., \& Eckert, E. Sequential effects in discrete trials instrumental escape conditioning. Journal of Experimental Psychology, 1974, 102, 473-483.

Seybert, J. A., Rigby, R. L., \& Mellgren, R. L. Spaced trial instrumental escape learning: Effects of magnitude and schedule of reinforcement. Animal Learning \& Behavior, 1976, in press. (b)

Shanab, M. E., Melrose, S., \& Young, T. The partial reinforcement effect sustained through blocks of continuous water reinforcement. Bulletin of the Psychonomic Society, $1975,6,261-264$.

(Received for publication March 26, 1976.) 